\title{
Second-Rank City Dynamics: Theoretical Interpretations Behind Their Growth Potentials
}

\author{
ROBERTO CAMAGNI \& ROBERTA CAPELLO
}

Politecnico di Milano, Milano, Italy

\section{The Missing Link Between Agglomeration Economies and Urban Dynamics: Theme of the Special Issue}

Second-rank cities are back on the academic scene, capturing the interest of scholars with their unexpected recent performance with respect to first-rank cities. In the data on average urban GDP growth in 139 European cities since 1996, the relatively strong position of large cities (over 1.5 million inhabitants) in national growth coincides with periods of fastest expansion, while at times of slowdown second-rank cities prevail (Camagni et al., 2014a). Especially in the recent period of economic downturn, second-rank cities have recorded annual GDP growth rates that are much less negative than those of capital cities; and in some European countries, like Austria and Germany, all cities have outperformed their capitals (Parkinson et al., 2014). This trend is not confined to Europe alone. In the USA, between 1969 and 2007, the largest eight Metropolitan Statisti-cal Areas (now on MSAs) grew by only one-third of the rate of the other three smaller MSA categories. Moreover, after 1990, the performance of the large MSAs was only slightly better, since their growth rates were still only about one-half of the average rates for the three smaller MSA size categories. The Big MSAs' growth rate barely exceeded those of nonmetropolitan areas: indeed, they even trailed the average growth rate of non-metropolitan areas (Partridge, 2010).

This is not the first time that the dynamics of second-rank cities have captured the interest of scholars; over time, different interpretations have been put forward of their relatively good performance. All of them are interesting, but none of them is fully convincing because they are linked more to cyclical than structural factors. During the 1980s, the fast growth of medium-sized cities in developing countries was explained as the conse- 
quence of repulsive forces from primate cities (Azzoni, 1986; Richardson, 1980; Townroe \& Kean, 1984). If this may have been an explanation in a particular period of time for emerging countries, it cannot be generalized to all periods and all countries.

At the end of the 1990s, in their book titled Second Tier Cities: Rapid Growth Beyond the Metropolis, Markusen et al. (1999, p. 3) once again asked the question "why newer, smaller cities had grown at the expense of older, larger ones, upsetting urban hierarchies". At that time, the reply was found in the role that second-rank cities were playing in the new industrial organization. They were identified as distinct areas of economic activity, constituting separate labour markets, where a specialized set of trade-oriented industries took root and flourished to establish employment and population-growth trajectories: the so-called new industrial spaces. Their success was strongly linked to the need of some industries to exploit localization (or district) economies, more than to the urbanization economies typical of large cities. Also this interpretation of secondrank city dynamics had more to do with a particular stage of industrial development; but it could not hold for all small- and medium-sized cities, in all countries and periods.

The most recent interpretation of the growth of second-rank cities has been rather different. It draws on the tradition of urban economic theory dealing with increasing/decreasing returns to urban size. In the recent European urban dynamics, in fact, the decline of large cities has been attributed to the emergence of decreasing returns to urban size, while second-rank cities have been interpreted as enjoying increasing returns, although they are far from the optimal city size envisaged by urban economic theory (Dijkstra et al., 2013). Agglomeration economies have been reprised as the main explanation for urban performance interpreted as a law of structural dynamics able to explain success and failure of cities.

Linking the explanation of urban dynamics to agglomeration theories seems the most interesting approach. However, as presented in Dijkstra et al., 2013, the mere linking of agglomeration economies to urban size in order to interpret urban performance is neither convincing nor sufficient, and calls for additional investigation of how agglomeration economies work. In such an approach, in fact, it is not clear why in certain periods of time large cities enter a period of decreasing returns, while in others they enjoy increasing returns. By the same token, it is not clear why, at a certain point in time, second-rank cities start enjoying agglomeration economies. This issue mixes two problems together: a structural and a cyclical one. The former concerns the existence of a theoretical explanation for how cities of different sizes can exploit increasing returns to urban scale (the "how" problem); the latter problem concerns the question of whether cities of different sizes are better suited for expansion or crisis periods, or for periods of emerging technologi-cal/ organizational paradigms or periods of paradigm diffusion (the "when" question). The "how" issue is logically propedeutical to, and more interesting than, the "when" issue, because descriptive evidence shows that there are some large cities able to play a role in their national economies in all periods, and some second-rank cities that still lag behind, suggesting that, for the same urban size, agglomeration economies play a positive role for some cities and not for others (Camagni et al., 2014b).

Our impression is that interpretation of the current dynamics in European urban systems - especially in the western part of Europe-would benefit from exploitation of the traditional concept of agglomeration economies. However, necessary for this purpose are more in-depth considerations on the nature, scope, intensity and causes of 
agglomeration economies which do not relate their existence solely to urban size. And this is where the main challenge for scholars lies: interpretation of the missing link between agglomeration economies and urban dynamics (Meijers, 2013).

The main aim of this special issue is to take up this challenge and to present the most advanced efforts made to interpret second-rank city dynamics and its role in the evolution of polycentric urban systems, by improving on existing agglomeration theories. In this way, the special issue contributes to the most advanced debate on how to link city and urban structure evolution to agglomeration economies.

\section{Recent Theoretical Interpretations of the Missing Link: A Common Effort by Different Approaches}

While the dynamics of "world cities" (Friedmann, 1986), "global cities" (Sassen, 1991), or "global-city regions" (Scott, 2001) was for long interpreted as stemming from their capacity to attract high-value functions, offering them a mix of talents and skills in a broad range of specialized fields, nowadays this seems to be no longer the case. Large cities do not grow faster than small- and medium-sized ones, and the current dynamics of European urban systems cannot be interpreted through the advantages of urban size. Empirical analyses of urban system dynamics, in fact, have shown that there are no regularities between the size and growth of cities, and they stress the need for an explanation of the missing link between agglomeration economies and urban dynamics.

The literature on agglomeration economies has traditionally highlighted three aspects that are inherently part of this concept: indivisibilities, synergies and physical proximity (Capello, 2009). Indivisibilities occur when the scale of agglomerated activities adds to productivity by causing shifts in a firm's production or cost curve (Cohen et al., 2009; Rosenthal \& Strange, 2001), but also shifts in aggregate urban efficiency that allow quantum jumps (leaps) in the infrastructure system. Indivisibilities prevail when an industrial perspective is taken: some sectors are more dependent on large-scale production processes than others, and some sectors derive many advantages from the presence of other sectors generating efficient and large "industrial complexes" (Isard \& Schooler, 1959). In light of these sectoral peculiarities, a large body of literature measures the extent to which the presence of a mix of industries or of a single industry generates greater agglomeration advantages (Carlino, 1980; Henderson, 1985). Synergies relate to the sociocultural dimension: trust, sense of belonging, cultural and religious homogeneity, these being typical features of agglomerated and specialized areas. They heighten the inten-sity of local market and non-market interactions, thus giving rise to increasing returns on production factors via transaction/production cost minimization for a given output (Becattini, 1989) or innovation-enhancing processes (Camagni, 1991; Storper, 1995). Proxi-mity is by definition linked to the geographical dimension of agglomeration and interaction effects: if information and transportation costs were nil, in the absence of scale economies there would be no reason to concentrate activities because doing so would not produce "economies". In this sense, agglomeration economies are "proximity economies".

These three elements explain the differences among the approaches to the sources of agglomeration economies, their nature, scope and intensity being explained from single perspectives: technical scale effects, easier market interactions, or limited distance friction. If one looks carefully into the most recent literature, a striking aspect emerges: whatever the approach taken, the most updated agglomeration theories undertake the 
explanation of urban dynamics through the concept of agglomeration economies by directly or indirectly taking up the challenge of explaining the missing link.

Table 1 sketches the new theories pertaining to the different approaches: the search for micro-economic foundations of agglomeration economies; the wider search for spatial interaction constituting the geographical foundations of agglomeration economies; the search for the macro-territorial foundations of agglomeration economies typical of recent regional economics contributions. As we see below, these approaches are rather different in nature. They capture different and complementary aspects of agglomeration economies, and stress particular elements that pertain to the foundations of agglomeration economies. Indivisibilities (labour-market indivisibilities, production indivisibilities) prevail in the micro-economic approach, allowing the reduction of production costs; physical proximity is the domain of the geographical approach; while synergy and interactions (limiting transaction costs) prevail in a macro-territorial approach. Notwithstanding these differences, common to all the approaches is the attempt to directly or indirectly explain urban dynamics through agglomeration economies, and they call for additional reflection on the concept itself of agglomeration economies in its traditional form. Advanced theoretical efforts already exist in all types of approaches applied to the dynamics of single cities, as well as to the evolution of the entire urban system, like regional and national polycentric urban structures or city networks.

\section{Micro-Economic Foundations of Agglomeration Economies: New Perspectives}

The early studies on agglomeration economies sought to explain theoretically and test empirically whether the scale of agglomerated activities added to productivity. The

Table 1. Interpretations of the missing link between agglomeration economies and urban dynamics

\begin{tabular}{|c|c|c|c|}
\hline & $\begin{array}{l}\text { Micro-economic } \\
\text { foundations }\end{array}$ & $\begin{array}{l}\text { Geographical } \\
\text { foundations }\end{array}$ & $\begin{array}{l}\text { Macro-territorial } \\
\text { foundations }\end{array}$ \\
\hline $\begin{array}{l}\text { Sources of advantages } \\
\text { internal to the city }\end{array}$ & $\begin{array}{l}\text { Heterogeneous } \\
\text { Industries } \\
\text { Industry mix }\end{array}$ & Milieu effects & $\begin{array}{l}\text { Quality of local factors, of } \\
\text { activities hosted, of } \\
\text { urban infrastructure }\end{array}$ \\
\hline $\begin{array}{l}\text { Sources of advantages } \\
\text { internal to the urban } \\
\text { system }\end{array}$ & $\begin{array}{l}\text { Agglomeration } \\
\text { shadows } \\
\text { (Growth shadows) }\end{array}$ & $\begin{array}{l}\text { Borrowed size } \\
\text { Externality fields }\end{array}$ & $\begin{array}{l}\text { Density and quality of } \\
\text { external linkages } \\
\text { City networks } \\
\text { (Network externalities) }\end{array}$ \\
\hline $\begin{array}{l}\text { Interpretation of the } \\
\text { link }\end{array}$ & $\begin{array}{l}\text { Specificities of } \\
\text { single industries } \\
\text { Spatial competition } \\
\text { effects }\end{array}$ & $\begin{array}{l}\text { A regionalization of } \\
\text { agglomeration } \\
\text { externalities }\end{array}$ & $\begin{array}{l}\text { Quality of territorial } \\
\text { capital assets }\end{array}$ \\
\hline $\begin{array}{l}\text { Interpretative logics: } \\
\text { from size to growth } \\
\text { through efficiency }\end{array}$ & $\begin{array}{c}\text { Size } \\
\downarrow \\
\text { Static efficiency } \\
\downarrow \\
\text { Competitiveness } \\
\downarrow \\
\text { Physical growth }\end{array}$ & $\begin{array}{c}\text { Size }+ \text { proximity } \\
\downarrow \\
\text { Externalities } \\
\downarrow \\
\text { Competitiveness } \\
\downarrow \\
\text { Physical growth }\end{array}$ & $\begin{array}{c}\text { Size }+ \text { territorial capital } \\
\downarrow \\
\text { Dynamic efficiency } \\
\downarrow \\
\text { Innovation } \\
\downarrow \\
\text { Physical growth and } \\
\text { structural evolution }\end{array}$ \\
\hline
\end{tabular}


well-known dichotomy drawn between urbanization and localization economies reflected these attempts, see among others (Carlino, 1980; Henderson, 1985; Hoch, 1972; Mera, 1973; Mills, 1970; Moomaw, 1983; Segal, 1976; Shefer, 1973; Sweiskauskas, 1975). The analytical framework used by this approach was in fact the identification of whether scale economies are related to the scale of the local specialization industry or to diversification and cross-fertilization among industries. Nevertheless, no consensus was achieved even when geo-referenced data on establishments and advanced spatial econometric techniques opened the way to more sophisticated analyses ${ }^{1}$ and still today many studies try to find the definitive answer to the question "who is right: Marshall or Jacobs?" (quoted from the title of Beaudry \& Schiffauerova, 2009).

In this approach, the sources of agglomeration economies are micro-economic in nature. They are identified in production cost minimization in accordance with the typical Marshallian tradition: input sharing interpreted in terms of increasing returns to scale in production; the local labour market as the size which allows a better match between employers' needs and workers' skills and reduced risks for both; home market effects and scale of pecuniary externalities (Krugman, 1991); superior technical knowledge achieved thanks to a large scale of operation; and highly specialized local labour markets (Rosenthal \& Strange, 2001).

The novelty in this field consists in investigation of the different ways in which the three well-known Marshallian forces-input sharing, market pooling and knowledge spillovers - play a role in agglomeration and locational choices according to the specificities of single industries (Faggio et al., 2013). Heterogeneity across industries seems pervasive, and the search for a "universal understanding of micro-economic foundations applying to all industries appears to be somewhat visionary and misleading" (Faggio et al., 2013, p. 4).

Even if not directly, this approach explains urban dynamics by considering the forces behind industry co-agglomeration in specific metropolitan areas. This approach suggests that it is not the size of a city, but rather the presence of the right combination of microeconomic elements, that explains its dynamics.

When considering the formation of large urban systems, the micro-economic approach focuses on the shadow effects that the presence of large cities exerts on surrounding smaller cities (Table 1). In their evolutionary model, Fujita and Mori $(1996,1997)$ assume the existence of a single city in which a variety of goods is produced, and a hinterland which produces agricultural goods. The presence of a population in the hinterland becomes of interest to entrepreneurs seeking market opportunities, and this is sufficient to develop the city. The overall population reaches a critical threshold at which equilibrium becomes unstable (Dobkins \& Ioannides, 2001), and a catastrophic bifurcation towards a duocentric system may occur. The location in which the new city is formed is not random; a core prediction of standard new economic geography is that the existence of shadow economies (Krugman, 1993) prevents urban areas from arising too close to other urban areas of equal or larger size owing to fierce spatial price competition. This is in line with the static perspective of the central place theory (Christaller, 1933).

According to these new perspectives, smaller cities have lower growth possibilities when located close to large cities. However, current urban systems seem highly diversified: they sometimes exhibit the existence of agglomeration shadows and sometimes oppose even positive effects of large cities on smaller ones (Partridge et al., 2009). Better interpretation of the reality requires additional theoretical insights into the geographical foundations of agglomeration economies. 


\section{Geographical Foundations of Agglomeration Economies: New Perspectives}

A different and complementary approach to the interpretation of agglomeration economies and urban dynamics looks for the so-called geographical foundations of agglomeration economies (Burger et al., 2014; Meijers, 2013) (Table 1). Traditionally, this approach has concerned itself with the proximity and non-market interactions among firms and people that give rise to "district" and "milieu" effects. These effects generate growth on the basis of both static and dynamic efficiency elements (Camagni, 1991). In more recent studies, this approach has highlighted the fact that urban agglomeration effects are not necessarily confined to the physical boundaries of a city but spill over to surrounding areas.

The starting point of this last approach is the concept of "borrowed size" developed by Alonso (1973); “ . . . a small city or a metropolitan area exhibits some of the characteristics of a larger one if it is near other population concentrations" (Alonso, 1973, p. 200). Behind this statement lies the claim that smaller places can "borrow" some of the agglomeration benefits of their large neighbours, while avoiding agglomeration costs. ${ }^{2}$

The physical distance at which agglomeration economies are able to exert their effects is the main element in this approach, which explains why smaller cities can sometimes grow thanks to (and at the expense of) nearby large cities. This approach can easily explain why smaller cities can grow more than larger cities, as well as why efficient polycentric urban structures at the local (regional) level exist (Brezzi \& Veneri, 2014; Agnoletti et al., 2014; Giffinger and Suitner, 2014). The concepts of "externality fields" (Phelps et al., 2001) or "regional externalities" (Parr, 2002) have been proposed to highlight the spatial coverage of urban advantages extending far beyond the city's boundaries.

The capacity of some specific second-rank cities to grow more than large cities is interpreted as stemming from the prevalence of "borrowed size" over "shadow economies". As Burger et al. claim, the strategic aspect to understand is which cities are advantaged and which cities are disadvantaged by spatial interdependencies. In other words, the question is which cities benefit from borrowed size and which face agglomeration shadows. The reply is complicated, and probably varies according to the urban function analysed. In the case of cultural amenities (museums, art galleries, etc.), Burger et al. (2014) make a first attempt to measure if and when borrowed size prevails over agglomeration shadows. They consider the sizes of cities and their positions in the urban hierarchy: larger cities within a functional urban area obtain the highest benefits from the size of the rest of the area in which they are located and from access to a large (inter)national market. Lower order places are less likely to borrow size from other places: they remain in the shadow of a first-rank city and undergo spatial competition effects. From this perspective, there-fore, the dynamics of second-rank cities can be better explained when a regionalization of urban externalities is conceptualized.

\section{Macro-Territorial Foundations of Agglomeration Economies: New Perspectives}

The last approach considered investigates the macro-territorial foundations of agglomeration economies, taking the city as the main unit of analysis, as do the large number of empirical studies measuring the scale effects of urban size (Henderson, 1974, 1985). In this tradition, the success of cities is attributed to the existence of agglomeration economies; conversely, urban decline is explained by the loss of increasing returns when a city reaches an excessive size. 
Recently, the idea that one single optimal city size exists has been abandoned; and so too has the opposite, too simplistic, view that infinite optimal city sizes exist, one for each city. A first theoretical solution resides in acknowledgement that other measurable factors affecting urban costs and benefits contribute together with pure size to the equili-brium size of the city (Camagni et al., 2013). A second solution starts from commonsense acknowledgement of the existence of different size classes of cities (small, medium, large) and the consideration that each class encompasses structurally similar cities (Camagni et al., 2014b). In fact, large cities are despecialized in terms of activity sectors, and they host high-level functions and occupations; medium-sized cities are generally more specialized and high-performing in the specialization sectors; small cities mainly host low-level skills and activities (Conti \& Dematteis, 1995).

In a simplified view, agglomeration economies may be taken for granted in small- and medium-sized cities; and only in large cities should the problem of a downturn in urban returns to scale eventually emerge. Assuming a more complex view, a new theoretical con-jecture claims that the exploitation of agglomeration economies is relatively smooth within the three/four traditional size classes (small, medium and large cities), but it implies the presence of specific limiting/enabling factors when cities approach some critical instability point (Camagni et al., 2014b). Therefore, cities may experience a halt in their growth path, and even a decline, irrespective of their size class in the absence of these conditioning factors. These factors are not really quantitative in nature; rather, they are qualitative, and quantum jumps in their endowment are needed at specific intervals if agglomeration economies are fully to exert their beneficial effects. The quality of the activities hosted, the quality of production factors, the density of external linkages and cooperation networks, the quality of urban infrastructure-for internal and external mobility, education, public services-are all factors enabling a long-term "structural dynamics" process (in the language of dynamic modelling) via what can be called a process of urban evolution and transformation.

In this sense, the explanation of a relatively good urban economic performance is not mechanically linked to the existence of agglomeration economies. Instead, this approach highlights the conditions under which agglomeration economies manifest themselves and may be fully exploited within each urban size class.

This approach confirms the existence of agglomeration economies, as well as the risk of agglomeration diseconomies, but this general law works within each class of cities. There are large cities able to escape agglomeration diseconomies, despite their huge size, and there are small cities that record decreasing returns in spite of their small size. The explanation of this apparent contradiction lies in the capacities of cities to overcome diseconomies of scale either by innovating in the functions they host or by launching cooperation through networks with other cities. In other words, the explanation lies in the presence of strategic territorial capital assets.

The concept of city networks, already present in the literature for many years (Camagni, 1993), recurs in the explanation of urban dynamics. The concept of "city networks" adds to that of "borrowed size" the idea that size can be borrowed not only thanks to physical proxi-mity to larger centres, but also thanks to relationships and flows of a mainly horizontal and non-hierarchical nature among complementary or similar centres, located far from each other, with the purpose of achieving network externalities (Camagni, 1993; Camagni \& Capello, 2004; Capello, 2000): a process that could be termed "borrowed functions". 
As Camagni et al. claim in this issue, these conceptual ideas help explain why cities of intermediate size are being increasingly looked upon as the places that could well host the growth of the years to come: limited city size, in fact, facilitates environmental equilibrium, efficiency of the mobility system and the possibility for citizens to maintain a sense of identity, provided that a superior economic efficiency is reached ("borrowed") through external cooperation with other cities located in the same region, or are distant but well connected with it.

In sum, this approach highlights that there exists a universal law of agglomeration economies that applies across all cities of any size, showing marked specificities within each size class. Within each city class, the quality of territorial capital assets-presence of high-value functions or networking and cooperation capabilities-is the condition sine qua non to avoid entering a phase of decreasing returns. In this perspective, smaller cities have high potential for growth if they are able to enter a virtuous and cumulative path of transformation and innovation through the exploitation of high-quality territorial assets in spite of their limited size.

\section{From Size to Growth Through Efficiency: A Comparison Among the Three Approaches}

The existence of these three approaches calls for a final comparison of their capacities to interpret urban dynamics through a different conceptualization of agglomeration economies.

In the logic of the micro-economic approach, the size of a city (and of industries within the city) determines its static efficiency; greater efficiency (productivity) generates firms' competitiveness, which in its turn explains growth opportunities for the place in which firms are located (Table 1). On this reasoning, pecuniary externalities play a major role in explaining agglomeration forces, restricting technological externalities to a specific and limited case: that of knowledge spillovers as sources of agglomeration economies (van Oort et al., 2014). The result is that "agglomeration advantage" refers only to a mere input-output relationship among clustered firms. The urban context does not influ-ence firms' performance, and it benefits only indirectly from a quantitative expansion. Cities are equated to agglomerations of firms; territory is downscaled to physical distance or geometric space.

In the geographical approach, interpretation of urban dynamics through agglomeration economies is based on a direct logical link: size and proximity generate technological externalities that explain urban competitiveness and therefore growth (Table 1). What allows the direct link to occur is the introduction of geographical space (geographical and cognitive proximity, and not solely the size of the urban production complex), as a source of externality and consequently the driving force behind the physical expansion of cities. However, the approach confines urban dynamics to the pure physical evolution of cities and urban systems, with no role assigned to their possible structural evolution and transformation.

Instead, internal structural transformation is central in the third approach, the macro-territorial approach. Thanks to its interpretation of the role of territorial capital in the capacity to exploit increasing returns to urban size, this approach is able to explain the structural dynamics of cities (and of urban systems) (Table 1). The capacity of cities to overcome diseconomies of scale is linked to the presence of strategic territorial capital assets allowing either innovation in the functions hosted or achievement of network externalities 
through cooperation with other cities. These elements directly affect urban competitiveness and growth, generating what in mathematical ecology is called "structural dynamics".

The differences underlined stress the strong complementarities among the three approaches; they all increase the interpretive capacity of agglomeration theories in the explanation of urban dynamics. But a direct link between agglomeration and urban dynamics is obtained only if technological externalities (mainly due to proximity and synergies) are considered. However, if agglomeration economies are to interpret structural evolutions and transformation, the role of the territory-defined as a set of cognitive, institutional, physical and natural local assets potentially generating competitiveness and utility flows to local communities- has to be taken into account.

\section{Initial Policy Implications}

An initial interesting and innovative policy lesson emerges from the present special issue. Betting and investing on second-rank cities seems to be a sensible strategy, provided that an evolutionary and innovation-oriented perspective is adopted. Particularly in emerging countries (like the EU Central Eastern European Countries), a national strategy based on the provision of basic accessibility and human capital infrastructure may prove more forward-looking with respect to investing only in a few capital cities. In fact, it may prevent the drawbacks inevitably linked to an excessive concentration of development resources in a few sports, namely wage and price increases, congestion and all diseconomies related to size and "sudden" urban growth (Camagni, 2008; Camagni \& Capello, 2013).

Investing in second-rank cities allows a wider and faster exploitation of dispersed and not fully exploited territorial capital assets, thanks to the capability of identifying and engaging these assets by local stakeholders and dynamic local élites, especially in times of consolidation and diffusion of technological paradigms, like the present knowledge economy one. This statement finds support and empirical corroboration in some very recent econometric research work on regional development and scenario foresights in the EU: a scenario encompassing consistent policies addressed at strengthening second-rank city-regions turns out to be more expansionary (and also more cohesive) than a scenario of concentration of public investments in capital cities and large, advanced city-regions (Camagni \& Capello, 2014). Similar policy messages come from many papers collected in this special issue (Agnoletti et al., 2014; Brezzi \& Veneri, 2014; Parkinson et al., 2014).

\section{Aims and Structure of the Special Issue}

This special issue goes deeply into the literature reviewed above by offering a collection of original papers pursuing two main interrelated aims. The first is to identify the reasons for the dynamics of second-rank cities. ${ }^{3}$ In particular, in light of the theoretical discussions presented in the previous sections, this issue contains papers that explore the geographical and macro-territorial foundations of agglomeration economies. The second aim is to highlight the role of second-tier cities in polycentric urban structures, capturing how urban externality fields and network externalities play a role in polycentric areas with different hierarchical structures. 
An introductory paper by Michael Parkinson, Richard Meegan and Jay Karecha provides data on the relatively good performance of second-rank cities (in their definition, non-capital cities) in Europe, and asks a simple but crucial question: why should governments invest outside their capitals? This is a question that assumes significant weight in a period of extremely scarce public resources like the one characterized by the current economic downturn.

The three papers that follow initiate analyses of how agglomeration economies explain second-rank urban dynamics. The paper by Roberto Camagni, Roberta Capello and Andrea Caragliu presents a macro-territorial conceptualization, claiming that secondrank cities may enter a phase of decreasing returns despite their size. The explanation of this apparent paradox is that cities are unable to improve territorial capital assets. They do not innovate in the functions that they perform, or in the organization of activities with other cities, when they are unable to offer these functions on their own. The main results of the empirical evidence reported on 136 European cities is that outperforming second-rank cities are those characterized by economies of scale, and that these economies of scale are related to territorial capital assets, like the level of functions and networks possessed by cities.

Martijn Burger, Evert Meijers, Marloes Hoogerbrugge and Jaume Masip Tresserra analyse the geographical foundations of agglomeration economies by treating the concept of "borrowed size" as essential for understanding urban patterns and dynamics in North-West Europe. More importantly, they make a first attempt to measure borrowed size vs. agglomeration shadows by resorting to the sizes of cities and their positions in the urban hierarchy as explanations for a city's capacity to borrow size. The main findings are in fact that the largest cities in a functional urban area obtain the highest benefits from the size of the rest of the area in which they are located and from access to a large (inter)national market. Lower order places are less likely to borrow size from other places. They remain in the shadow of a first-rank city and undergo spatial competition effects.

The paper by Frank van Oort, Stefan de Geus and Teodora Dogaru focuses on the agglomeration circumstances influencing economic growth across European urban regions. The novelty of the paper is that it suggests a possible way out of the current seemingly locked-in debate on the relation between agglomeration and growth, which is ambiguous and indecisive with regard to whether specialization or diversity is facilitated by (sheer) urbanization. The debate on whether specialization or diversity explains urban dynamics is resolved by the introduction of concepts like related and unrelated variety in the empirical modelling of growth across European regions, arguing that it is not simply the presence of different technological or industrial sectors that will yield positive results; rather, sectors require complementarities that exist in terms of shared competences (Frenken et al., 2007).

In the second part of the special issue, attention is concentrated on the role of secondrank cities in polycentric urban structures at different (national and regional) levels. Monica Brezzi and Paolo Veneri present an empirical analysis on the role of national and regional polycentricity in explaining the economic well-being of regions and nations in all OECD countries. Interestingly, national polycentricity (i.e. a network of cities) is found to be positively correlated with high per capita GDP levels. Instead, at the regional level, polycentric urban structures seem to have lower per capita GDP levels than monocentric ones: pure agglomeration economies seem to generate higher economic efficiency and greater well-being than borrowed size. 
Chiara Agnoletti, Chiara Bocci, Sabrina Iommi, Patrizia Lattarulo and Donatella Marinari conduct an interesting discussion on economic efficiency (in terms of the competitiveness of urban services produced) and sustainability (in terms of land consumption and urban fragmentation) of different hierarchical models within polycentric urban structures. Drawing on a rich dataset on Italian cities, the empirical analysis shows that regions with a polycentric structure consisting of small- and medium-sized cities are rather competitive and sustainable. This leads to the rather new and interesting result that the size of cities alone does not explain differences in the economic and environmental performances of polycentric urban systems.

Last, but not least, Rudolf Giffinger and Johannes Suitner debate whether metropolization should be analysed in terms of a process rather than a state. This approach is essential to grasp the structural differences in the metropolization process in Europe, and to highlight the fact that European city-regions have reached different stages of polycentric metropolitan development. This perspective is also an essential foundation for learning processes in the governance of future polycentric metropolitan development.

\section{Notes}

1. See among others Ciccone (2002), Ciccone and Hall (1996), Ellison and Glaeser(1997), Henderson (2003), Rosenthal and Strange (2001, 2003).

2. Some scholars have already suggested that agglomeration costs are more confined to city boundaries than agglomeration benefits (Parr, 2002).

3. The papers contained in this special issues were presented in draft versions at the international seminar on

"Welfare and competitiveness in the European polycentric urban structure", organized by IRPET, held in Florence on 7 June 2013. The editors are grateful to Patrizia Lattarulo of IRPET for her scientific and financial help in the organization of the international seminar.

\section{References}

Agnoletti, C., Bocci, C., Iommi, S., Lattarulo, P. \& Marinari, D. (2014) First and second tier cities in regional agglomeration models, European Planning Studies. doi:10.1080/09654313.2014.905006

Alonso, W. (1973) Urban zero population growth, Daedalus, 102(4), pp. 191-206.

Azzoni, C. (1986) Indústria e reversiăo de polarizaciõn de Brasil, Essays in Economics no. 58, Institute of Economic Studies, University of Saõ Paulo, Saõ Paulo.

Beaudry, C. \& Schiffauerova, A. (2009) Who's right, Marshall or Jacobs? The localization versus urbanization debate, Research Policy, 38(2), pp. 318-337.

Becattini, G. (1989) Sectors and/or districts: Some remarks on the conceptual foundations of industrial economics, in: E. Goodman \& J. Bamford (Eds) Small Firms and Industrial Districts in Italy, pp. 123-135 (London: Routledge).

Brezzi, M. \& Veneri, P. (2014) Assessing polycentric urban systems in the OECD: Country, regional and metropolitan perspectives, European Planning Studies. doi:10.1080/09654313.2014.905005

Burger, M. J., Meijers, E. J., Hoogerbrugge, M. M. \& Tresserra, J. M. (2014) Borrowed size, agglomeration shadows and cultural amenities in Western Europe, European Planning Studies. doi:10.1080/09654313. 2014.905002

Camagni, R. (1991) Technological change, uncertainty and innovation networks: Towards a dynamic theory of economic space, in: Camagni, R. (Ed) Innovation Networks: Spatial Perspectives, pp. 121-144 (London: Belhaven-Pinter).

Camagni, R. (1993) From city hierarchy to city networks: Reflection about an emerging paradigm, in: T. Lakshmanan \& P. Nijkamp (Eds) Structure and Change in the Space Economy: festschrifts in Honour of Martin Beckmann, pp. 66-87 (Berlin, DE: Springer-Verlag). 
Camagni, R. (2008) Towards a conclusion: Regional and territorial policy recommendations, in: R. Capello, R. Camagni, U. Fratesi \& B. Chizzolini (Eds) Modelling Regional Scenarios for the Enlarged Europe, pp. 283-306 (Berlin: Springer-Verlag).

Camagni, R. \& Capello, R. (2004) The city network paradigm: Theory and empirical evidence, in: R. Capello, P. Nijkamp (Eds) Urban Dynamics and Growth: Advances in Urban Economics, pp. 495-532 (Amsterdam: Elsevier).

Camagni, R. \& Capello, R. (2013) Regional innovation patterns and the EU regional policy reform: Towards smart innovation policies, Growth and Change, 44(2), pp. 355-389.

Camagni, R. \& Capello, R. (2014) Rationale and Design of EU Cohesion Policies in a Period of Crisis. Paper presented at the International Seminar of GRINCOH, Milan, February 27-28.

Camagni, R., Capello, R. \& Caragliu, A. (2013) One or infinite optimal city sizes? In search of an equilibrium size for cities, The Annals of Regional Science, 51(2), pp. 309-341.

Camagni, R., Capello, R. \& Caragliu, A. (2014a) Structural Dynamics of Second vs. First Rank Cities: Similar Laws, High Specificities. Paper presented at the 60 NARSC conference, Atlanta, GA, November $13-16$.

Camagni, R., Capello, R. \& Caragliu, A. (2014b) The rise of second-rank cities: What role for agglomeration economies? European Planning Studies. doi:10.1080/09654313.2014.904999

Capello, R. (2000) The city network paradigm: Measuring urban network externalities, Urban Studies, 37(11), pp. $1925-1945$.

Capello, R. (2009) Indivisibilities, synergy and proximity: The need for an integrated approach to agglomeration economies, Tijdschrift voor Economische en Sociale Geographie (TESG), 100(2), pp. 145-159.

Carlino, G. (1980) Contrasts in agglomeration: New York and pittsburgh reconsidered, Urban Studies, 17(3), pp. 343-351.

Christaller, W. (1933) Die Zentralen Orte in Süddeutschland [The Central Places in Southern Germany], Wissenschaftlische Buchgesellschaft, Darmstadt, English edition (1966), Prentice-Hall, Englewood Cliffs, NJ.

Ciccone, A. (2002) Agglomeration effects in Europe, European Economic Review, 46(2), pp. 213-227.

Ciccone, A. \& Hall, R. E. (1996) Productivity and the density of economic activity, American Economic Review, 86(1), pp. 54-70.

Cohen, J. \& Paul Morrison, C. (2009) Agglomeration, productivity and regional growth: Production theory approaches, in: R. Capello \& P. Nijkamp (Eds) Handbook of Regional Dynamics and Growth: Advances in Regional Economics, pp. 101-117 (Cheltenham: Edward Elgar).

Conti, S. \& Dematteis, G. (1995) Enterprises, systems and network dynamics: The challenge of complexity, in: S. Conti, E. Malecki \& P. Oinas (Eds) The Industrial Enterprise and Its Environment: Spatial Perspectives, pp. 217-242 (Aldershot: Avebury).

Dijkstra, L., Garcilazo, E. \& McCann, P. (2013) The economic performance of European cities and city regions: Myths and realities, European Planning Studies, 21(3), pp. 334-354.

Dobkins, L. H. \& Ioannides, Y. M. (2001) Spatial interaction among U.S. cities: 1900-1990, Regional Science and Urban Economics, 31(6), pp. 701-731.

Ellison, G. \& Glaeser, E. L. (1997) Geographic concentration in US manufacturing industries: A dartboard approach, Journal of Political Economy, 105(5), pp. 889-927.

Faggio, G., Silva, O. \& Strange, W. (2013) Heterogeneous Industries. Paper presented at the 60th North American Regional Science Conference, Atlanta, GA, November 13-16.

Frenken, K., van Oort, F. G. \& Verburg, T. (2007) Related variety, unrelated variety and regional economic growth, Regional Studies, 41(5), pp. 685-697.

Friedmann, J. (1986) The world city hypothesis, Development and Change, 17(1), pp. 69-83.

Fujita, M. \& Mori, T. (1996) The role of ports in the making of major cities: Self-organization and hub effects, Journal of Development Economics, 49(1), pp. 93-120.

Fujita, M. \& Mori, T. (1997) Structural stability and evolution of urban systems, Regional Science and Urban Economics, 27(4), pp. 399-442.

Giffinger, R. \& Suitner, J. (2014) Polycentric metropolitan development: From structural assessment to processual dimension, European Planning Studies. doi:10.1080/09654313.2014.905007

Henderson, J. (1974) The sizes and types of cities, The American Economic Review, 64(4), pp. 640-656.

Henderson, J. (1985) Economic Theory and the Cities (Orlando, FL: Academic Press).

Henderson, J. V. (2003) Marshall's scale economies, Journal of Urban Economics, 53(1), pp. 1-28.

Hoch, I. (1972) Income and city size, Urban Studies, 9(3), pp. 299-328. 
Isard, W. \& Schooler, E. (1959) Industrial complex analysis, agglomeration economies and regional developmentj, Journal of Regional Sciencel, 1(2), pp. 19-33.

Krugman, P. (1991) Geography and Trade, (Cambridge, MA: MIT Press).

Krugman, P. (1993) First nature, second nature and metroplitan location, Journal of Regional Science, 33(2), pp. 129-144.

Markusen, A., Lee, Y.-S. \& Di Giovanna, S. (Eds) (1999) Second-Tier Cities: Rapid Growth Beyond the Metropolis, (Minneapolis, MN: University of Minnesota Press).

Meijers, E. (2013) Cities Borrowing Size: An Exploration of the Spread of Metropolitan Amenities across European Cities. Paper presented at the Association of American Geographers Annual Meeting, Los Angeles, April 9-13.

Mera, K. (1973) On the urban agglomeration and economic efficiency, Economic Development and Cultural Change, 21(2), pp. 309-324.

Mills, E. (1970) Urban density functions, Urban Studies, 7(1), pp. 5-20.

Moomaw, R. (1983) Is population scale worthless surrogate for business agglomeration economies? Regional Science and Urban Economics, 13(4), pp. 525-545.

Parkinson, M., Meegan, R. \& Karecha, J. (2014) City size and economic performance: Is bigger better, small more beautiful or middling marvellous? European Planning Studies. doi:10.1080/09654313.2014.904998 Parr, J. B. (2002) Agglomeration economies: Ambiguities and confusions, Environment and Planning A, 34(4), pp. 717-731.

Partridge, M. (2010) The dueling models: NEG vs amenity migration in explaining U.S. engines of growth, Papers in Regional Science, 89(3), pp. 513-536.

Partridge, M., Rickman, D. S., Ali, K. \& Olfert, M. R. (2009) Do new economic geography agglomeration shadows underlie current population dynamics across the urban hierarchy? Papers in Regional Science, $88(2)$, pp. $445-467$.

Phelps, N. A., Fallon, R. J. \& Williams, C. L. (2001) Small firms, borrowed size and the urban-rural shift, Regional Studies, 35(7), pp. 613-624.

Richardson, H. W. (1980) Polarization reversal in developing countries, Papers of the Regional Science Association, 45(1), pp. 67-85.

Rosenthal, S. S. \& Strange, W. C. (2001) The determinants of agglomeration, Journal of Urban Economics, 50(2), pp. 191-229.

Rosenthal, S. S. \& Strange, W. C. (2003) Geography, industrial organization, and agglomeration, Review of Economics and Statistics, 85(2), pp. 377-393.

Sassen, S. (1991) The Global City (Princeton, NJ: Princeton University Press).

Scott, A. (2001) Global City-Regions (Oxford: Oxford University Press).

Segal, D. (1976) Are there returns to scale in city size? Review of Economics and Statistics, 58(3), pp. 339-350.

Shefer, D. (1973) Localization economies in SMSA'S: A production function analysis, Journal of Regional Science, 13(1), pp. 55-64.

Storper, M. (1995) La Géographie des Conventions: Proximité Territoriale, Interdépendences Non-Marchandes et Développement Economique, in: A. Rallet \& A. Torre (Eds) Economie Industrielle et Economie Spatiale, pp. 111-128. (Paris: Economica).

Sweikauskas, L. (1975) The productivity of city size, Quarterly Journal of Economics, 89(3), pp. 393-413.

Townroe, P. \& Kean, D. (1984) Polarization reversal in the state of sao paulo, Brazil Regional Studies, 18(1), pp. $45-54$.

Van Oort, F., de Geus, S. \& Dogaru, T. (2014) Related variety, regional economic growth and place-based development-strategies in urban networks in Europe, European Planning Studies. doi:10.1080/ 09654313.2014 .905003 